\title{
Política Urbana no Rio de Janeiro: entre a cidade do plano e a cidade real
}

\author{
Angela Moulin Simões Penalva Santos ${ }^{1}$ \\ Mariana Gomes Peixoto Medeiros ${ }^{2}$ \\ Pedro Henrique Ramos Prado Vasques ${ }^{3}$
}

\begin{abstract}
RESUMO
$\mathrm{O}$ artigo analisa aspectos do impasse da política urbana brasileira. Por um lado houve um notável avanço normativo nos últimos 25 anos, após a entrada em vigor da Constituição de 1988, em particular após a regulamentação dos novos instrumentos jurídicos e urbanísticos pelo Estatuto da Cidade em favor do direito à cidade. Por outro lado, as práticas de políticas públicas urbanas capturadas pelo capital imobiliário se renovaram e vêm logrando utilizar a normatividade urbanística para promover seus interesses através da especulação fundiária. $\mathrm{O}$ resultado é uma distância entre a cidade pretendida pelo plano e a produção da cidade real. Tais reflexões assumem maior concretude ao serem associadas às práticas em curso, indicando novos desafios a serem enfrentados pela política urbana. A experiência de gestão pública da Região Metropolitana do Rio de Janeiro e do Município do Rio de Janeiro foram utilizados para referir-se às transformações recentes no planejamento urbano.

Palavras-chave: Política urbana; Rio de Janeiro; Região Metropolitana do Rio de Janeiro.
\end{abstract}

\begin{abstract}
The article examines aspects of the Brazilian urban policy stalemate. On one hand there was a notable regulatory advance in the past 25 years after the enactment of the 1988 Constitution, particularly after the regulation of new legal and urban instruments by the City Statute Act in favor on behalf of the right to the city. Moreover, practices of urban policies captured by real estate capital renewed it and it is managing to use urban normativity to promote their interests through land speculation. The result is a gap between the desired city by the plan and the actual production of the city. Such considerations assume greater concreteness when associated with the practice, stating new challenges to be faced by urban policy. The experience of public management in Rio de Janeiro Metropolitan Area and the city of Rio de Janeiro were used to refer to the recent changes in urban planning.
\end{abstract}

Keywords: Urban policy; Rio de Janeiro; Rio de Janeiro Metropolitan Area.

\footnotetext{
${ }^{1}$ Pós-doutora em Planejamento Urbano e Regional (USP). Professora Associada da UERJ.

${ }^{2}$ Mestranda em Direito da Cidade - UERJ.

${ }^{3}$ Mestrando em Direito da Cidade - UERJ.
} 


\section{Introdução}

A intensa urbanização da população brasileira resultou em formação de grandes metrópoles dentre as quais se destaca o Rio de Janeiro, capital do país por quase 200 anos. O crescimento da metrópole carioca extravasou as fronteiras municipais e formou uma enorme "cidade" com mais de 11 milhões de habitantes. Tal "cidade" é constituída de 19 municípios que compõem a Região Metropolitana do Rio de Janeiro.

Como no Rio de Janeiro, outras metrópoles tornaram-se núcleo de áreas urbanas conurbadas e experimentaram intensa crise urbana, o que gerou um movimento social em favor da reforma urbana. Durante os anos 1980, a redemocratização política levou à promulgação de uma nova Constituição que recepcionou novos direitos sociais e fortaleceu institucionalmente o município, tornando-o ente federativo e responsável pela política urbana, em consonância com a luta do movimento pela reforma urbana.

Após 25 anos da entrada em vigor da Constituição, quais seriam os resultados destes avanços institucionais? Neste artigo pretendemos analisar aspectos da política urbana tomando como referência o caso da metrópole carioca.

O artigo é composto de 3 seções, além desta Introdução. Na primeira, serão discutidos aspectos do planejamento urbano, cujo conteúdo atual, como política urbana, avançou muito em relação a sua perspectiva original.

Na segunda seção, focaliza-se o caso do Rio de Janeiro. Numa parte inicial, analisa-se a institucionalidade da Região Metropolitana do Rio de Janeiro, formada por municípios que deveriam cooperar para dar efetividade aos princípios do planejamento urbano, tais como explicitados na Lei do Estatuto da Cidade. Na segunda parte desta segunda seção, o foco é o Município do Rio de Janeiro, questionando a atuação do governo como regulador e fomentador do desenvolvimento municipal, com pouco comprometimento com a periferia metropolitana. A terceira e última seção é dedicada às conclusões.

\section{Planejamento urbano: para além da regulação urbanística}

O Planejamento Urbano surgiu como intervenção pública no espaço urbano quando as cidades tornaram-se locus do capitalismo industrial e o emprego no setor primário foi insuficiente para manter contingente significativo de população na área rural. A concentração demográfica fez, por sua vez, emergir novos e complexos problemas de reprodução social, como os desafios na área da mobilidade, habitação e saneamento ambiental. 
Inicialmente identificado como política higienista, o planejamento urbano logo seria considerado uma técnica para expandir e/ou criar novas cidades. Mas ficaria evidente que uma nova sociabilidade emergia, o que significa considerar novas formas de representação política do fenômeno urbano, especialmente considerando os casos das grandes cidades (Santos, 2006).

As condições de reprodução social nas cidades fariam com que o conflito entre trabalho e capital tivessem sua dimensão territorial, tornando o controle sobre o solo urbano e as políticas de infraestrutura urbana em elementos constitutivos do "direito à cidade". Tal evidência colocaria em xeque a abordagem tecnicista do planejamento urbano e faria emergir a luta pela participação social nas políticas urbanas.

O entendimento do que seja o "direito à cidade" passou a incluir acesso a direitos sociais, recepcionados nas constituições nacionais, como nos casos de Educação, Saúde, Assistência Social e também a Moradia.

A criação da Agência Habitat/ONU foi um importante instrumento de disseminação de uma nova e ampliada agenda de direitos dos residentes urbanos. $\mathrm{O}$ direito à moradia, cuja origem está na própria constituição da ONU, em 1948, ganharia um sentido preciso, como "moradia adequada". Por esta denominação inclui-se não apenas a edificação, mas também a regularização do terreno onde esteja edificada a moradia, além de acesso a infraestruturas necessárias para a vida cotidiana, caso das redes de energia, saneamento, transportes.

Diante destas transformações, o planejamento urbano deixou de estar identificado com construção de novas cidades ou com projetos arquitetônicos idealizados, mas deslocados das dinâmicas social e econômica responsáveis pela emergência da "questão urbana". Entretanto, o planejamento urbano também não pode prescindir de uma visão de futuro, se quer manter-se como instrumento orientador da expansão das cidades.

Neste contexto, duas visões passam a disputar o sentido do planejamento urbano: a abordagem da "urbanização social" e o "empreendedorismo urbano". A primeira está identificada com a agenda dos direitos, um dos quais o direito à cidade. Mas, é a segunda que vem predominando na administração das cidades, em particular, das metrópoles, como é o caso atual da cidade do Rio de Janeiro que vem sofrendo intenso processo de transformação socioterritorial sustentada no projeto de sediar os Jogos Olímpicos de 2016.

E, no entanto, cada uma ilumina uma parte da "questão urbana". O urbanismo social remete para a necessidade de administrar a cidade de modo a torná-la acessível aos seus residentes, isto é, permitindo-lhes acesso à terra e à infraestrutura urbana. Já o planejamento 
por projeto facilita mobilizar recursos em escala suficiente para implementar grandes blocos de investimentos de difícil "engenharia financeira".

Cabe ainda lembrar que o planejamento urbano também envolve dimensões distintas, que precisam ser consideradas: a regulação do uso do solo e o fomento ao desenvolvimento urbano.

A regulação urbanística é representada pela legislação urbanística visando o controle do processo de expansão urbana, em prol do direito a cidades social e ambientalmente sustentáveis. Trata-se de uma dimensão de direito "em negativo", impedindo usos incompatíveis e em favor da manutenção do interesse coletivo.

Já o fomento ao desenvolvimento urbano envolve "prestações positivas" do Estado, isto é, alocação de recursos orçamentários para financiar a expansão da infraestrutura. Num contexto de crescimento extensivo da mancha urbana, extravasando para outros municípios e formando metrópoles muito mais complexas do que as cidades nucleares, torna-se necessária a intervenção pública para viabilizar a produção de bens públicos, como são os casos da malha viária e da rede de saneamento. Tais investimentos pesados, por sua vez, tendem a produzir vetores de expansão urbana suscitando respostas do mercado imobiliário que acabam por gerar mais demandas por infraestrutura urbanística. O resultado tende a envolver mais "engenharia financeira" para administrar uma cidade cujos compromissos não são simples gestão local, mas sim parcelas significativas da economia do país.

Conforme evidência encontrada pela ONU em seus relatórios anuais sobre a situação da população mundial, está em curso um processo de concentração da população em grandes cidades na maior parte dos estados nacionais. Estas grandes cidades concentram o PIB nacional, além da população de seus países. Nestas condições, tais cidades tornam-se centros econômicos e seus governantes atores políticos de grande relevância no cenário nacional (Santos, 2012).

Fenômeno semelhante, ainda que em escala menor, ocorre no interior do território nacional, constituído pelos estados. Em cada uma destas unidades da federação, há uma rede urbana constituída de cidades de diferentes pesos demográfico e econômico, sendo que as mais importantes tendem a se tornar agentes que articulam o território estadual. Administrar essas cidades requer que seus prefeitos assumam responsabilidades relativas às condições de vida de sua população, mas também que cuidem da adequada inserção das economias municipais nas redes de geração de produção, maximizando suas potencialidades. Não se trata de objetivos concorrentes, mas devem ser complementares. 
E quais devem ser os compromissos das prefeituras em relação ao "planejamento urbano"?

No Brasil, a lei federal 10.257/01, chamada Estatuto da Cidade, define o Plano Diretor como o instrumento jurídico por meio do qual os governos municipais estabelecem seus objetivos de política urbana. Tais objetivos devem se submeter aos princípios desta legislação, destacando-se a "função social da propriedade" e a "função social cidade", introduzindo aí a orientação para que os municípios se comprometam com a regularização fundiária.

O Plano Diretor, no entanto, não se resume a regular o uso do solo urbano, mas também inclui diretrizes para o desenvolvimento urbano ao tratar do território municipal, e não urbano, como seu objeto. Incluir a área rural no Plano Diretor acaba por expressar de forma mais direta o tema do desenvolvimento territorial, que pode ou não estar restrito às fronteiras municipais.

E aqui introduzimos a questão da forma jurídica de ordenamento do território nacional. Segundo o artigo 182 da Constituição de 1988, o município é o ente federativo responsável pela política urbana. A União manteve sua competência pelo estabelecimento de normas gerais de política urbana (e o fez pela edição do Estatuto da Cidade), ficando os estados com a responsabilidade pelas competências residuais (as que não são exclusivas da União ou dos municípios).

Cabe lembrar que os avanços nos direitos sociais e difusos incluídos na Constituição ampliaram muito o entendimento do que seja um dos elementos constitutivos mais relevantes do planejamento urbano, isto é, o direito à moradia, que passou a ser definido por "moradia adequada". Como já mencionado anteriormente, não se trata apenas da edificação, a unidade habitacional, mas sim de uma moradia regularizada em termos fundiários e de acesso às redes de infraestrutura urbana. Portanto, o compromisso das prefeituras com o planejamento urbano avançou para muito além da tradicional regulação urbanística, uma vez que passou a incluir investimento pesado em redes de infraestrutura cujo financiamento também está muito além da autonomia financeira municipal.

Nestas condições, o enorme avanço normativo que o Movimento Nacional pela Reforma Urbana logrou instituir na Constituição da República/1988 e na Lei do Estatuto da Cidade constitui apenas uma parte dos desafios da política urbana atual. Falta avançar na regulamentação municipal desta legislação, bem como na articulação entre entes federativos 
para que cooperem em soluções de políticas públicas territoriais cujos impactos extravasem o município.

\section{Os desafios da política urbana na metrópole carioca}

\subsection{A (falta) de coordenação municipal na Região Metropolitana do Rio de Janeiro}

Como é possível verificar através da análise dos exemplos de outras regiões metropolitanas, a institucionalidade que as compõe é consideravelmente diversificada. É possível encontrar estruturas metropolitanas voltadas para a consecução de projetos específicos (e.g. Alemanha), modelos que partiram de estruturas centralizadas para a descentralização (e.g. Espanha, Madrid) e vice-versa (e.g. Londres, Marseille-Aix) ${ }^{4}$ e, inclusive, composições metropolitanas com um grau de institucionalidade reduzido (e.g. Estados Unidos) (Vasco, 2007). A grande variedade de resultados obtidos a partir da utilização de cada modelo decorre, em grande parte, do momento político, social e econômico em que são planejadas e implementadas.

No caso do Rio de Janeiro, a RMRJ foi criada pela Lei Complementar n. 20/1974. Sua atual composição, determinada atualmente pela Lei Complementar n. 133/2009, é definida pelos seguintes 19 (dezenove) municípios: Rio de Janeiro, Belford Roxo, Duque de Caxias, Guapimirim, Itaboraí, Japeri, Magé, Maricá, Mesquita, Nilópolis, Niterói, Nova Iguaçu, Paracambi, Queimados, São Gonçalo, São João de Meriti, Seropédica, Tanguá e Itaguaí. Todavia, a despeito de a política metropolitana brasileira haver sido inicialmente concebida a partir de uma estrutura extremamente centralizada (Garson, 2009) - descentralizada após a promulgação da Constituição Federal de 1988 (Santos, 2008) -, no caso da RMRJ, as sucessivas alterações em sua composição, forma de organização e atuação (Leis Complementares n. 64/90, 87/97, 97/2001, 105/2002, 130/2009 e 133/2009) são um forte indicativo que nos orienta no sentido de afirmar que, tanto na época de sua criação como hoje, o grau de institucionalidade da RMRJ é consideravelmente reduzido, incapaz de manter coeso um grupo de municípios consideravelmente heterogêneos.

Esse entendimento sobre o reduzido grau de institucionalidade da RMRJ é corroborado, ainda, pelo relatório “Território, coesão social e governança democrática: Rio de

\footnotetext{
4 Relatório de Pesquisa: Novas governanças para as áreas metropolitanas: o panorama internacional e as perspectivas para o caso brasileiro. Coord.: Luiz César de Queiroz Ribeiro, Elaboração: Joeroen Johannes Klink. Observatório das Metrópoles, 2008.
} 
Janeiro, São Paulo, Belo Horizonte, Curitiba, Porto Alegre, Salvador, Recife, Belém, Natal, Goiânia, Maringá” elaborado pelo Observatório das Metrópoles em 2009, que identifica “(...) na Região Metropolitana do Rio de Janeiro uma forte fragmentação institucional e a inexistência de um projeto da gestão metropolitana. As instâncias e mecanismos mais efetivos de interação e de concertação entre municípios metropolitanos no que concerne à gestão urbana e do território são poucos e apresentam baixa eficácia". 5

Dessa forma, como se demonstrará a seguir, a despeito de o governo do Estado haver instituído uma secretaria específica para tratar das demandas regionais metropolitanas, qual seja, a Secretaria de Desenvolvimento Regional, Abastecimento e Pesca (SDRA), criada em dezembro de 2010, pouco foi efetivamente realizado no que se refere à gestão da RMRJ como um todo, reforçando a ausência de elementos institucionais consistentes capazes de articular a coordenação intermunicipal para gestão do território a partir da perspectiva regional.

Contudo, apesar das críticas à gestão da RMRJ, não é possível deixar de mencionar algumas atividades realizadas pelo governo do Estado do Rio de Janeiro no sentido de provocar o debate acerca do desenvolvimento institucional do referido território regional. Nesse sentido pode-se destacar - para fins exemplificativos - a série de eventos realizados com o objetivo de discutir as questões metropolitanas, denominados "Diálogos Metropolitanos". ${ }^{6}$ Interessante notar que o mesmo modelo - i.e., de realização de eventos na Assembleia Legislativa - foi adotado quando do processo de elaboração do Plano Diretor Metropolitano de Belo Horizonte. Entretanto, importante destacar a baixa/ausente presença de representantes dos governos municipais nos referidos eventos, a despeito de, segundo informações informalmente prestadas pelo governo estadual, tais autoridades locais haverem sido formalmente convidadas.

Como brevemente contextualizado, a criação das regiões metropolitanas através da adoção de uma política territorial centralizada, somada ao fato de o Município do Rio de Janeiro haver sido a capital do país durante o período anterior, forneceu elementos que permitiram que a capital do Estado fosse conduzida a uma condição de proeminência extrema, corroborando para que a RMRJ - desde sua criação - já nascesse muito polarizada

5 Projeto Observatório das Metrópoles: Território, coesão social e governança democrática. Rio de Janeiro, São Paulo, Belo Horizonte, Curitiba, Porto Alegre, Salvador, Recife, Belém, Natal, Goiânia, Maringá. Arranjos Institucionais para a Gestão Metropolitana - RELATÓRIO DE PESQUISA. Coordenador Geral: Orlando Alves dos Santos Junior. Outubro, 2009.

6 Para mais informações sobre os eventos: <http://www.actamarketing.com.br/riometropole/> (Acesso em 01.11.12). 
economicamente.

O Município do Rio de Janeiro concentra a maior população, a maior parte das atividades econômicas, a maior rede de infraestrutura, e se constitui em uma das cidades de maior expressão cultural e política do país. De fato, excluindo-se Duque de Caxias e Niterói, que em 2010 concentravam respectivamente o segundo e quinto maiores PIBs municipais do Estado (CEPERJ, 2010), o conjunto dos outros municípios metropolitanos apresentam problemas de falta de recursos fiscais e financeiros, de pobreza de parte significativa da população e de falta de estruturas administrativas qualificadas para formular e executar políticas públicas.

Retomando a afirmação acerca da ausência de uma perspectiva holística sobre a gestão metropolitana no Estado do Rio de Janeiro, passamos a analisar a atuação da SDRA, atualmente, o instrumento institucional com maior capacidade de articulação de políticas regionais intermunicipais no âmbito da fragilizada RMRJ.

Conforme informações disponibilizadas em entrevista realizada com o atual subsecretário adjunto, a SDRA estaria agindo de forma estratégica. Isto é, participando dos grandes empreendimentos em planejamento e instalação no Estado do Rio de Janeiro por meio da análise e combate às externalidades negativas e fragilidades por eles identificadas. ${ }^{7}$ Nesse sentido, a SDRA possui grupos de trabalho voltados para os seguintes empreendimentos/regiões no Estado do Rio de Janeiro: (i) Arco Metropolitano, (ii) Complexo Petroquímico do Estado do Rio de Janeiro (COMPERJ), (iii) Porto do Açu, (iv) Porto de Sepetiba, (v) Região Serrana e (vi) Angra 3. Com desempenho atualmente focado para a região do COMPERJ, a SDRA tem participado - como se vê, setorialmente - na elaboração de um plano diretor específico ${ }^{8}$ para a região que compõe o Consórcio Intermunicipal de Desenvolvimento do Leste Fluminense (CONLESTE). ${ }^{9}$ Outra demonstração da atuação

7 Interessante destacar na fala do subsecretário que a SDRA estaria funcionando, ainda, como espécie de interlocutor entre as demandas dos grupos sociais afetados e as empresas privadas responsáveis pela condução dos grandes empreendimentos no Estado. Tal atuação teria de ser observada de modo mais aprofundado para ser criticamente avaliada.

8 Isto é, um plano específico para os seguintes municípios: seis da região chamada de Leste Metropolitano do Estado (Niterói, São Gonçalo, Itaboraí, Rio Bonito, Maricá e Tanguá), mais alguns da Região das Baixadas Litorâneas, que, por sua vez, agrupa a Microrregião da Bacia de São João e a Região dos Lagos (Cachoeiras de Macacu, Casimiro de Abreu, Silva Jardim, Araruama, Saquarema), dois da Baixada Fluminense (Guapimirim e Magé) e dois da Região Serrana Fluminense (Nova Friburgo e Teresópolis).

9 O CONLESTE foi constituído em 2006 e é composto por 11 (onze) municípios (Itaboraí, São Gonçalo, Niterói, Tanguá, Guapimirim, Magé - municípios metropolitanos - e Maricá, Rio Bonito, Silva Jardim, Cachoeira de Macacu e Casimiro de Abreu). O CONLESTE definiu como objetivos a gestão associada de 
estratégico-setorial da SDRA está na elaboração de um plano diretor específico para a região do Arco Metropolitano ${ }^{10}$ que, a despeito de ser qualificado pelos próprios membros do atual governo estadual como espécie de macrozoneamento regional, mais uma vez conduz o planejamento metropolitano à luz de, basicamente, aspectos econômicos. ${ }^{11}$

Assim, além da crítica óbvia sobre a inexistência de uma visão holística acerca do processo de gestão do território metropolitano, a atuação estratégico-setorial tem sua atenção voltada para regiões em que o setor econômico já está canalizando fortes investimentos, o que, por sua vez, vai de encontro ao preconizado pelo Estatuto da Cidade (Lei n. 10.257/2001). Nesse sentido, essa performance - i.e., basicamente condicionada à presença de capital privado - denota uma preferência na gestão do espaço urbano que, apesar de exprimir necessidades legítimas - tanto do poder econômico como das comunidades locais impactadas -, é insuficiente para conduzir a gestão do espaço metropolitano com vistas a beneficiar a todos os integrantes da RMRJ e não só aqueles envolvidos nos planos de investimento do capital privado. Apesar de a referida atuação setorial possuir inúmeros benefícios, as demais áreas da RMRJ - distantes dos processos econômicos atualmente verificados/planejados no Estado - permanecem alijadas da lista de prioridades do Executivo estadual, reforçando novamente a condição de fraca relação interinstitucional entre os municípios da RMRJ.

Em outras palavras, ao que parece, a foco da SDRA atualmente está voltado para articular os interesses do capital privado e não em traduzir e implementar as necessidades regionais dos municípios da RMRJ. Essa condição de disparidade de forças - em função da presença do capital privado - pode ser exemplificada através das polarizadas estatísticas dos municípios que compõem a RMRJ. O alto grau de desigualdade entre os municípios e o apelo do gestor estadual à atuação praticamente restrita às áreas onde o capital privado está presente agravam a desvantagem competitiva dos municípios menores e menos capazes de atrair a manifestação dos demais entes federativos para suas necessidades - que, em algumas situações, inclusive são [necessidades] comuns aos demais.

serviços públicos, o planejamento estratégico integrado, políticas públicas regionais e o intercâmbio de experiências.

10 O arco metropolitano atravessa os seguintes municípios da RMRJ: Itaboraí, Guapimirim, Magé, Duque de Caxias, Nova Iguaçu, Japeri, Seropédica, Itaguaí, totalizando 2.2 milhões de habitantes, segundo a Secretaria de Obras do Estado do Rio de Janeiro.

11 O arco metropolitano atenderá, entre outros, aos seguintes grandes empreendimentos: (i) Porto de Itaguaí, (ii) Complexo Industrial e Siderúrgico de Santa Cruz, (iii) Complexo Petroquímico de Duque de Caxias, (iv) COMPERJ e (v) Plano de Antecipação da Produção de Gás (PLANGÁS). 
Importante ressaltar que não se está aqui defendendo a presença hegemônica do Poder Executivo estadual como condição para a existência de uma RMRJ para os municípios marginalizados do processo de expansão econômica festejado por alguns outros municípios do Estado do Rio de Janeiro. Contudo, como a própria Constituição Federal de 1988 definiu em seu art. $25, \S 3^{\circ}$, compete aos Estados, por meio de lei complementar, instituir as regiões metropolitanas com a finalidade de organizar, planejar e executar as funções públicas de interesse comum. Nesse sentido, a ausência do Executivo estadual (ou ainda pior, sua presença seletiva) faz prevalecer uma perspectiva setorial não inclusiva que, na sua condição de intermediador das relações intermunicipais, acaba por minar, em grande medida, a capacidade de articulação da RMRJ. Essa relação de intermediação seletiva restringe a viabilidade de cooperação intermunicipal apenas a condições muito específicas, excluindo do diálogo os municípios que não preenchem tais requisitos (e.g., presença do capital privado).

Além do referido foco de atuação acima debatido, faz-se necessário mencionar a existência de algumas iniciativas metropolitanas - não setoriais e/ou estratégicas - para gestão de determinadas funções públicas de interesse comum que poderiam ser desenvolvidas pela SDRA de modo a fomentar o interesse à articulação intermunicipal no âmbito da RMRJ. Nesse sentido, é possível destacar - como exemplo negativo de gestão metropolitana (i.e., de atuação inexpressiva) - o setor de transportes urbanos que, apesar de dispor de uma agência metropolitana, a Agência Metropolitana de Transportes Urbanos (AMTU) ${ }^{12}$ - criada em 26.01.2007 -, possui níveis de integração muito baixos e sem nenhum esquema de priorização dos sistemas de transporte coletivo, caracterizados por sua elevada intermodalidade. A coordenação dessa política pública urbana através da via interinstitucional com a articulação da SDRA poderia, ao menos em tese, trazer ganhos expressivos para toda RMRJ.

Outro exemplo se refere à gestão metropolitana de recursos ambientais como, por exemplo, (i) dos resíduos sólidos - através de articulação promovida pela Secretaria Estadual do Ambiente $(\mathrm{SEA})^{13}$-, (ii) de áreas especialmente protegidas - por meio do ICMS Ecológico - e (iii) dos recursos hídricos - através dos comitês de bacia hidrográfica. ${ }^{14} \mathrm{~A}$

12 A AMTU é uma entidade colegiada representativa do estado, dos municípios que compõem a região metropolitana e das instituições - públicas ou privadas - responsáveis pelo planejamento, gestão e operação de transportes públicos, na região.

13 Nesse sentido, ver as leis estaduais n. 6.333/12 e 6.334/12.

14 Podem-se citar, por exemplo, o (i) Comitê de Bacia do Rio Guandu, criado em 2002, que abrange 12 municípios do estado, além das bacias do Rio da Guarda e Guandu-Mirim, e está diretamente ligado à questão da proteção de mananciais, já que o Rio Guandu é fonte de abastecimento para grande parte dos municípios da Região Metropolitana; e (ii) Comitê da Região Hidrográfica da Baía de Guanabara e dos 
Secretaria Estadual do Ambiente vêm conduzindo sua atuação no sentido de proporcionar inúmeros benefícios ambientais para os municípios que compõem a RMRJ. Todavia, semelhante à questão da mobilidade urbana, uma atuação coordenada - a partir da SDRA -, com o objetivo de fomentar o desenvolvimento de um arcabouço institucional forte para lidar com as demandas metropolitanas, poderia gerar não só os referidos benefícios ambientais, mas também o fortalecimento de uma estrutura institucional que poderia ser utilizada para o fomento e desenvolvimento de outras políticas públicas de natureza metropolitana.

Assim, a partir da sucinta análise acima realizada, é possível verificar que o poder público vem conduzindo a gestão regional do espaço metropolitano de forma estratégica e empreendedora priorizando os espaços em que há presença do capital privado. Essa postura, que acaba por perpetuar um histórico de atrofia e impedimento de desenvolvimento de uma institucionalidade metropolitana, também é verificada no âmbito do Município do Rio de Janeiro. Enquanto os executivos estadual e municipal atuam em conjunto para a formulação e implementação de políticas públicas urbanas, essas se verificam especificamente orientadas em um modelo de empreendedorismo urbano que, entre outros, amplia cenários de segregação espacial e favorece um modelo de renovação urbana dirigido a atender os interesses do capital privado, indo de frontal encontro aos preceitos que defendem o acesso universal à cidade.

\subsection{A regulação urbanística na metrópole carioca e suas bases no "empreendedorismo} urbano"

A cidade do Rio de Janeiro passa por intenso processo de transformação socioterritorial, cujo desenvolvimento urbano vem sustentado atualmente no projeto de sediar os Jogos Olímpicos de 2016 e de ser uma das cidades-sede da Copa do Mundo FIFA de 2014. ${ }^{15}$ Esse processo, no entanto, apesar de todo o avanço legislativo das últimas décadas ter como horizonte o "urbanismo social" e a conquista dos direitos correlatos ao direito à cidade, vem se desenvolvendo com suas bases primordialmente no chamado "empreendedorismo urbano".

sistemas lagunares de Maricá e Jacarépaguá, criado em 2005, que abrange áreas de 17 municípios: Rio de Janeiro, Duque de Caxias, Nilópolis, São João de Meriti, Mesquita, Belford Roxo, Nova Iguaçu, Petrópolis, Magé, Guapimirim, Cachoeiras de Macacu, Itaboraí, Tanguá, Rio Bonito, São Gonçalo, Niterói e Maricá.

15 O Rio de Janeiro irá sediar nos próximos anos dezenas de eventos internacionais, entre eles, a Copa das Confederações da FIFA Brasil em 2013, a Copa do Mundo da FIFA em 2014 e os Jogos Olímpicos e Paraolímpicos de 2016. Mais informações em http://www.rio.rj.gov.br/web/riotur/exibeconteudo?article$\mathrm{id}=2284151$ 
O planejamento empreendedorista tem sido utilizado pelos gestores municipais como única forma possível de financiar projetos de desenvolvimento urbano, o que traz uma série de consequências, principalmente nas questões há anos incluídas nas lutas dos movimentos sociais, como o Fórum Nacional de Reforma Urbana, configurando uma espécie de volta no tempo com relação aos problemas relacionados à segregação socioespacial.

Assim, remete-se ao retorno de práticas que fazem recordar a política higienista de planejamento, de forma incompatível com o novo contexto jurídico-urbanístico constitucional inaugurado com a Constituição de 1988 e reafirmado no Estatuto da Cidade: há atualmente vasta legislação que promove a inclusão dos moradores pobres, do direito à cidade, da função social da propriedade e da cidade, da gestão democrática e da proteção jurídica da posse (Fernandes, 2006).

No compasso com a adoção do modelo neoliberal de gestão pelo Estado brasileiro no início dos anos 1990, emergiu na cidade um novo modelo de política urbana, que propôs mudanças na sua estrutura e gestão, com a redefinição do papel do governo local: o executivo municipal, como agente potencializador do desenvolvimento econômico da cidade, adota uma postura empreendedora, estratégica e inevitavelmente afinada com o discurso empresarial (Santos, 2006).

Esse novo perfil de governança hoje atinge um alto grau de institucionalidade, com a realização de vultosos projetos urbanísticos que resignificam os espaços, levando a cabo um verdadeiro processo de renovação urbana. Neste sentido, os megaeventos esportivos - Copa do Mundo da FIFA de 2014 e os Jogos Olímpicos de 2016 - que serão sediados na cidade, se configuram como uma forma de atração de investimentos para este fim, sendo responsáveis assim, em grande parte, pela definição das áreas-alvo de reestruturação urbana no território.

Apesar de tal ideário ter sido consubstanciado na cidade inicialmente no antigo Plano Estratégico de 1993, na gestão do prefeito César Maia, muito da sua essência permanece na atualidade durante a gestão do prefeito Eduardo Paes, atingindo grande concretude, como se observa nos projetos urbanísticos em curso na cidade. O executivo municipal, nos últimos 10 anos, reformulou sua estrutura institucional, redistribuiu competências, elaborou novas normas e políticas públicas, estabeleceu parcerias público-privadas e criou novos instrumentos urbanísticos (Vainer, 2011).

Sobre o empreendedorismo urbano, Rose Compans (2005) observa que no estímulo ao desenvolvimento econômico caberia à iniciativa municipal, além do apoio institucional e da identificação de oportunidades de investimentos, o ordenamento urbanístico e paisagístico das 
áreas públicas, sendo prioridade o restabelecimento da "ordem urbana". Igualmente, o uso sistemático das "tendências globais" como parâmetros do desenvolvimento local demonstra que o paradigma adotado é, nitidamente, o da cidade global, cuja lógica de organização social, econômica e espacial deve estar subordinada ao mercado global (Sassen, 1998).

As cidades portuárias, como o Rio de Janeiro, se apresentam como lugares estratégicos para investimentos e têm propiciado a formação de cidades globais ou mundiais, ${ }^{16}$ isto é, cidades-sede do dinamismo das trocas internacionais, alvo de uma série de transformações de cunho econômico, social, político e urbanístico e ponto de intensa gravitação nos territórios nacionais e de grande destaque nos fluxos macrorregionais e internacionais. Para tanto, o poder público se empenha na atração de investimentos e capitais e na exaltação da vocação turística e dos atributos naturais, ao mesmo tempo em que realiza enormes investimentos em infraestrutura e nos setores de serviços financeiros, socioculturais e de fluidez territorial (transportes e comunicações).

Numa conjuntura marcada pela desindustrialização, degradação dos centros urbanos, crescente terceirização e precarização da força de trabalho e aumento do trabalho informal, as novas estratégias de planificação são orientadas para conter a desordem urbana, porém com a "nova roupagem" do empreendedorismo urbano, que pretende alterar as engrenagens da máquina cultural e estética e dar uma nova imagem à cidade. E é com esta "nova roupagem", com a preparação da cidade para a sua afirmação no cenário competitivo das cidades globais, que uma série de projetos urbanísticos são previstos, alguns deles já em fase de execução.

$\mathrm{Na}$ metrópole carioca, além de projetos de requalificação urbana e melhoria de infraestrutura, há também outros programas de governo que vêm sendo implementados para esses fins. Neste pacote podemos destacar: a revitalização de áreas com potencial cultural e turístico como o bairro da Lapa, a renovação da região portuária da cidade através do megaprojeto Porto Maravilha, o Programa Morar Carioca (uma espécie de continuação em novos moldes do Programa Favela Bairro), o programa Minha Casa, Minha Vida (tem como objetivo a construção de habitação de interesse social subsidiada para famílias de até 10 salários-mínimos), e a construção de grandes estruturas viárias - Transcarioca, Transoeste e Transolímpica, além de duas novas linhas metroviárias.

16 Embora os conceitos de "cidade global" ou "cidade mundial" tenham surgido na década de 1980, fazendo referência às transformações urbanas dentro do quadro da reestruturação produtiva em curso nos países centrais, eles se generalizam como categoria analítica a partir da década de 1990. Nesse sentido, ressaltamos o trabalho desenvolvido por Sassen (1991), que atribui essa denominação a cidades como Nova Iorque, Tóquio, Londres, Paris, Frankfurt, Los Angeles, Cingapura, Hong Kong, Miami, Cidade do México, São Paulo e Bombaim. 
Cabe aqui destacar o projeto de desenvolvimento urbano com grande fomento atualmente na cidade, a Operação Urbana Consorciada (OUC) do Porto Maravilha. Tal projeto, para ser plenamente desenvolvido, contou com o ajuste legislativo de vários marcos legais municipais referentes às parcerias público-privadas, inclusive o Plano Diretor, que foi reeditado em 2011 (Lei Complementar n. ${ }^{\circ}$ 11/2011), com a criação de novos instrumentos da política urbana, como os institutos jurídicos e políticos da própria OUC, da outorga onerosa do direito de construir e de alteração de uso, da cessão ou qualquer outra forma de transferência do direito de construir, além dos direitos de superfície e de preempção (Freitas, 2012).

Nesta toada, fica evidente, no caso do marco legislativo do Porto Maravilha, uma deturpação dos instrumentos da política urbana obtidos inicialmente como avanços legislativos pró-“urbanismo social”, mas que acabaram sendo usados em pról do modo empreendedorista de gestão. O empresariamento das cidades não é somente a assunção de um modo estratégico-empresarial de governá-las; é também, como consequência, a instituição de parcerias público-privadas visando aumentar sua competitividade no nicho mercadológico e o repasse do território (cuja gestão já se torna um passivo para os governos) à iniciativa privada conforme suas possibilidades especulativas.

De acordo com Harvey (2005, 2011), o que vem sendo estimulado atualmente na cidade é o desenvolvimento da capacidade localizadora de valorização do capital, como fazem o turismo, o espetáculo e os megaeventos. A paisagem geográfica da acumulação do capital está em perpétua evolução, em grande parte sobre o impulso das necessidades especulativas de acumulação adicional (incluindo a especulação sobre a terra) e, só secundariamente, considerando as necessidades dos habitantes. $\mathrm{O}$ significado mais profundo que as pessoas atribuem a sua relação com a terra, lugar, casa e práticas de habitação vai de encontro a essa política de mercado sobre a terra urbana.

Assim, as intervenções urbanísticas planejadas para a cidade do Rio de Janeiro embasadas no empreendedorismo urbano e, atualmente utilizando os preparativos para os megaeventos esportivos de 2014 e 2016 como justificativa, vêm trazendo profundas mudanças para o cotidiano de seus moradores. Para a cidade-sede dos megaeventos esportivos é indesejável que se dê visibilidade às mazelas sociais e à "desordem" urbana: uma nova estética se impõe, e requer a expulsão da população de baixa renda para as regiões periféricas da cidade, pouco atrativas ao capital imobiliário.

Os efeitos mais graves deste comportamento do poder público municipal são o 
aumento do custo de vida e a segregação da população de baixa renda para a periferia. Seja por gentrificação (Smith, 2006) - também chamada de "expulsão branca" - ou por meio das políticas de remoção forçada já em curso, através das quais os moradores mais carentes que habitam "informalmente" as áreas-alvo dos planejadores empreendedores neste processo vêm sofrendo violações diretas ao direito à moradia e à cidade, podendo ser identificadas graves violações relacionadas aos princípios da função social da cidade e da gestão democrática da cidade (Estatuto da Cidade).

Neste sentido, a gestão do prefeito Eduardo Paes acentuou brutalmente essa política; em um primeiro momento através do discurso da ordem e da lei - vide a implementação das Unidades de Polícia Pacificadora $^{17}$ e do Choque de Ordem $^{18}-$, depois, após as chuvas de abril de 2010 (que causaram deslizamentos e mortes em várias cidades do Estado, deixando milhares de pessoas desabrigadas), com o discurso do risco. ${ }^{19}$ Hoje, o discurso da ordem se atualizou incorporando o progresso e desenvolvimento da cidade.

Em conjunto com o discurso da ordem urbana e do progresso da cidade, e com a proximidade da realização dos megaeventos, diversas comunidades foram removidas ou estão ameaçadas de remoção, sem nenhum respeito aos direitos fundamentais dos moradores. São exemplos emblemáticos comunidades como a da Restinga, Vila Harmonia e KM 35, todas na Avenida das Américas, onde se realizam as obras da via Transoeste; os casarões no Largo do Campinho, por onde passará a chamada Transolímpica; ou a comunidade denominada Metrô Mangueira, próxima ao Maracanã, na qual o município distribuiu laudos de interdição genéricos, sem realizar vistorias técnicas nas casas, e sequer apresentou o projeto para a área, havendo somente as suspeitas dos moradores de que ali será construído um estacionamento para o novo Maracanã. ${ }^{20}$

17 "A Unidade de Policiamento Pacificadora é um novo modelo de segurança pública e de policiamento que promove a aproximação entre a população e a polícia, aliada ao fortalecimento de políticas sociais nas comunidades. Ao recuperar territórios ocupados há décadas por traficantes e, recentemente, por milicianos, as UPPs levam a paz às comunidades (...). A Polícia Comunitária é um conceito e uma estratégia fundamentada na parceria entre a população e as instituições da área de segurança pública”. Descrição obtida na página da UPP na internet: http://upprj.com/wp/?page_id=20. Última consulta em 21.09.11.

18 Operação da Prefeitura do Rio de Janeiro que tem por objetivo combater a desordem urbana e pequenos delitos a fim de evitar a sensação de insegurança pública e estimular "os bons princípios das ruas". http://www.rio.rj.gov.br/web/guest/exibeconteudo?article-id=87137. Última consulta em 21.09.11.

19 A Lei Orgânica do Município do Rio de Janeiro, que em seu artigo 429 consagra o Princípio da Não Remoção, prevendo como única hipótese de excepcionalidade a este princípio a constatação de risco para a vida dos habitantes da localidade em questão.

20 Alguns destes casos estão relatados na segunda edição do Dossiê Megaeventos e Violações de Direitos Humanos no Rio de Janeiro, elaborado pelo Comitê Popular Rio da Copa e das Olimpíadas e disponível em http://comitepopulario.files.wordpress.com/2013/05/dossie_comitepopularcoparj_2013.pdf 
Podemos observar, portanto, que o caráter empreendedorista das intervenções no urbano somado às práticas antidemocráticas assumidas pelo executivo municipal só podem gerar maior segregação na cidade do Rio de Janeiro. O aquecimento do mercado imobiliário segue sem que se utilize de qualquer instrumento de controle da especulação. Pelo contrário, a finalidade dos empreendimentos urbanísticos é justamente uma intensa valorização imobiliária e no setor de serviços que atraia investidores privados e moradores de maior poder aquisitivo para a cidade. $^{21}$

Ficam evidentes os riscos de se incorporarem, no planejamento urbano, conceitos reificados das cidades mundiais, globais, estratégicas, que levam a um processo de “urbanismo negocial”, com objetivos mais econômicos do que urbanísticos (Maricato, 1997). Está em curso, portanto, uma orientação na política urbana municipal, que vem adotando um modelo de gestão urbana fundado na parceria público-privada e na flexibilização do controle público sobre o uso e ocupação do solo. Ou seja, o desenvolvimento em curto prazo cobra seu preço: a subordinação do planejamento urbano aos interesses privados e a consequente valorização imobiliária e expulsão das camadas populares para regiões periféricas, ou pelas remoções forçadas ou pela silenciosa "gentrificação".

As estratégias de resistência das comunidades atingidas, por sua vez, como a mobilização coletiva e a articulação com movimentos populares são alternativas buscadas hoje na perspectiva de criação de um projeto que faça frente ao modelo de cidade imposto pelo poder hegemônico. A organização comunitária atualmente começa a discutir a proposição de um projeto alternativo para as obras de infraestrutura de adaptação da cidade para os grandes empreendimentos e os megaeventos, que dê voz aos moradores e concilie o desenvolvimento à permanência dos moradores e da cultura local. ${ }^{22}$

21 No caso da região portuária, por exemplo, em entrevista no jornal $O$ Globo de 5 de julho de 2011, Jeb Brugmann, urbanista e consultor da prefeitura, afirma que será muito difícil conter a especulação imobiliária no Porto e, para que os moradores originários permaneçam no local, o SEBRAE fará um trabalho de capacitação dos mesmos para que sua renda cresça "junto com o desenvolvimento da área".

22 Um exemplo é o Plano Popular da Vila Autódromo, um projeto alternativo à decisão pela remoção da comunidade localizada em área próxima ao Parque Olímpico, feito em parceria entre a comunidade e o Laboratório ETTERN/IPPUR/UFRJ. Disponível em: http://comitepopulario.files.wordpress.com/2012/08/planopopularvilaautodromo.pdf 


\section{Conclusões}

Como apresentado, os anos 1980 foram marcados pela redemocratização política que conduziu à promulgação de uma nova Constituição Federal. Esse marco regulatório nacional foi responsável pela recepção de uma série de direitos sociais e fortaleceu institucionalmente a figura do município. A edição de uma nova Carta Magna, democrática e essencialmente preocupada com questões difusas e sociais, abriu espaço para o desenvolvimento de outros atos normativos que, naquele momento, eram considerados indicadores para avaliação de um suposto processo de avanço institucional.

Dentre os instrumentos normativos desenvolvidos, destacou-se, no âmbito desse trabalho a Lei Federal n. 10.257/01, o Estatuto da Cidade, que introduziu de forma sistematizada uma série de ferramentas urbanísticas possíveis de serem utilizadas para a gestão da cidade. Ocorre que, por se tratar de um instrumento, as alternativas legais introduzidas pelo Estatuto da Cidade podem ser apropriadas por qualquer que seja a visão do planejamento urbano predominantemente no momento. Assim, a despeito de a regulação urbanística visar o controle do processo de expansão urbana, em prol do direito a cidades social e ambientalmente sustentáveis, mecanismos jurídicos como, por exemplo, o Plano Diretor podem ser repensados e modificados para conduzir a gestão urbana através de abordagens mais dinâmicas e menos inclusivas como no caso de medidas de gestão adotadas por políticas públicas de corte "empreendedorista".

Sob esse aspecto da apropriação do instrumento jurídico para a produção de um específico e determinado espaço urbano, orientado para favorecer apenas os espaços iluminados pelo capital privado, é possível analisar o atual estágio de articulação entre os entes federativos que compõem a Região Metropolitana do Rio de Janeiro, bem como a atual gestão empreendedora da capital carioca.

Sob esse aspecto, a RMRJ, criada em meados da década de 1970, pouco conseguiu efetivamente evoluir - no que toca ao aspecto de cooperação interinstitucional - após a crise da década de 1980. A diminuição de investimentos por parte da União, a transferência da competência para criação de regiões metropolitanas, o fortalecimento dos municípios e a condição histórica associada ao Município do Rio de Janeiro haver sido capital do país durante período significativo de tempo são fatores que dificultaram significativamente a articulação institucional da RMRJ. 
Dessa forma, desde a extinção da FUNDREM até o ano de 2010, com a criação da SDRA, a RMRJ permaneceu completamente desprovida de orientação institucional. Sem uma política pública voltada para a gestão regional do espaço, a institucionalidade da RMRJ teve pouco espaço para se desenvolver de forma sólida. Assim, o que se verificou ao longo desse período foi a coordenação de grupos de municípios isolados na tentativa de gerir de forma compartilhada determinados serviços (e.g. transporte, resíduos etc.).

Com a criação da SDRA esperava-se que o governo estadual resgatasse as forças necessárias para conduzir uma política pública regional que integrasse toda a RMRJ. Contudo, como se buscou demonstrar através da análise apresentada neste trabalho, o espaço metropolitano carioca vem sendo gerido de forma estratégica, orientada para a promoção de interesses próprios do capital privado, articulados para favorecer um desenvolvimento de curto prazo, indo de encontro aos preceitos que defendem o acesso universal à cidade.

No caso da cidade do Rio de Janeiro, esta vem passando por um intenso processo de transformação socioterritorial cujo desenvolvimento urbano vem sustentado atualmente no projeto de sediar os Jogos Olímpicos de 2016 e de ser uma das cidades-sede da Copa do Mundo FIFA de 2014. O modelo de planejamento empreendedorista, como demonstrado por este trabalho, vem sendo utilizado como forma de financiar projetos de desenvolvimento urbano. Esse novo perfil de gestão do espaço urbano acaba por trazer consequências significativas que resignificam os espaços, levando a cabo um verdadeiro processo de renovação urbana. Entende-se, desse modo, que o que vem sendo estimulado atualmente na cidade é o desenvolvimento da capacidade localizadora de valorização do capital, como fazem o turismo, o espetáculo e os megaeventos.

A experiência de gestão pública na capital e na Região Metropolitana do Rio de Janeiro sugerem que o planejamento urbano tem sido utilizado como linguagem discursiva para legitimar ações em sentido contrário àquele pretendido pelo movimento nacional pela reforma urbana. Evidentemente que não se trata de nenhuma novidade, há muitos casos paradigmáticos de captura do poder público pelos interesses empresariais na produção do espaço urbano, como foram as reformas Haussmann, em Paris, e Pereira Passos, no Rio.

Uma das hipóteses que visa conferir força a esse modelo de gestão empreendedora por parte dos executivos estadual e municipal no Rio de Janeiro está associada aos impactos decorrentes das ações dos Estados - com o objetivo de socorrer seus sistemas econômicos após eclosão da crise financeira de 2008. A partir deste momento, grandes potências afetadas, tal como os Estados Unidos, passaram a socorrer as corporações prejudicadas pela crise. Esta 
intervenção estatal foi defendida como necessária para salvar o capitalismo, mitigando a crise de desemprego. Em tal contexto, o planejamento empreendedorista tornou-se mais um instrumento do arsenal da luta contra a crise, o que lhe conferiu maior força diante das normas protetivas dos direitos sociais e difusos.

Tal estratégia de enfrentamento de crises capitalistas, no entanto, contribui para alimentar a crise urbana, cobrando um preço elevado demais para ser suportado pela maior parte da população. Nestas condições, usufruir dos espaços públicos urbanos tende a se tornar um luxo para poucos, capazes de suportar o encarecimento do preço da terra urbana, que passa a ser apropriada como instrumento de acumulação de riqueza, de reserva de valor. Daí que o planejamento urbano volta a ser demandado desde a perspectiva do direito à cidade.

\section{Referências bibliográficas}

CEPERJ, Fundação Centro Estadual de Estatísticas, Pesquisas e Formação de Servidores Públicos do Rio de Janeiro. Produto Interno Bruto dos Municípios - 2010. Estado do Rio de Janeiro, $2010 . \quad$ Disponível em http://www.ceperj.rj.gov.br/ceep/pib/PIB_municipios_RJ_2010.pdf (Acessoｅm 13.06.13)

COMPANS, Rose. Empreendedorismo urbano: entre o discurso e a prática. São Paulo: Editora UNESP, 2005.

FERNANDES, Edesio. A nova ordem jurídicourbanística no Brasil. In: FERNANDES, E; ALFOSIN, B. (Orgs.). Direito Urbanístico. Estudos Brasileiros e Internacionais. Belo Horizonte: Del Rey, 2006.

FREITAS, Odair. Marco legal do "Porto Maravilha" (A administração gerencialista e a transformação da cidade em mais uma mercadoria). Anais do II ENANPARQ. Natal: 2012.

GARSON, Sol. Regiões metropolitanas: por que não cooperam? Rio de Janeiro: Letra Capital / Observatório das metrópoles; Belo Horizonte, MG: PUC, 2009.

GOUVÊA, Ronaldo Guimarães. A questão metropolitana no Brasil. Rio de Janeiro: Editora FGV, 2005.

HARVEY, David. O Enigma do Capital e as crises do capitalismo. São Paulo: Boitempo, 2011. . A produção capitalista do espaço. São Paulo: Annablume, 2005. 
MARICATO, Ermínia. Brasil 2000: qual planejamento urbano? Cadernos IPPUR. Ano XI, n. 1 e 2. Rio de Janeiro: IPPUR, jan.-dez. 1997.

SANTOS, Angela Moulin S. Penalva. Finanças Públicas: uma análise da autonomia financeira dos municípios brasileiros na primeira década do século XXI. Revista do Tribunal de Contas do Estado do Rio de Janeiro vol. 7, n. 1, Rio de Janeiro: O Tribunal, jan./jun. 2012.

. Município, Descentralização e Território. Rio de Janeiro: Editra Forense, 2008.

. Planejamento urbano: para quê e para quem? Revista de Direito da Cidade. n. 1, vol. 1, Rio de Janeiro/UERJ, 2006.

SASSEN, Saskia. As Cidades na Economia Mundial. São Paulo: Studio Nobel, 1998.

The Global City: New York, London, Tokyo. Princeton: Princeton University Press, 1991.

SMITH, N. A gentrificação generalizada: de uma anomalia local à "regeneração" urbana como estratégia urbana global. In: BIDOU-ZACHARIASEN, C. (Org.). De volta à cidade. São Paulo: Annablume, 2006.

VAINER, Carlos. Cidade de Exceção: reflexões a partir do Rio de Janeiro. In: XIV ENCONTRO NACIONAL DA ANPUR, 2011. Disponível em http://www.opp.ufc.br/urbano04.pdf (Acesso em 08/06/2013).

VASCO, José Alexandre. Formas especiais de organização do território na federação brasileira. Dissertação (Mestrado em Direito). Programa de Pós-Graduação em Direito. Rio de Janeiro: Universidade do Estado do Rio de Janeiro, 2007. 415f. 